\title{
Wnt5a attenuates the pathogenic effects of the Wnt/ $\beta$-catenin pathway in human retinal pigment epithelial cells via down-regulating $\beta$-catenin and Snail
}

\author{
Joo-Hyun Kim ${ }^{1, \#}$, Seoyoung Park ${ }^{1, \#}$, Hyewon Chung ${ }^{2}$ \& Sangtaek Oh ${ }^{1, *}$ \\ ${ }^{1}$ Department of Bio and Fermentation Convergence Technology, Kookmin University, Seoul 02707, ${ }^{2}$ Department of Opthalmology, Konkuk \\ University School of Medicine, Seoul 05066, Korea
}

\begin{abstract}
Activation of the $\mathrm{Wnt} / \beta$-catenin pathway plays a pathogenic role in age-related macular degeneration (AMD) and is thus a potential target for the development of therapeutics for this disease. Here, we demonstrated that Wnt5a antagonized $\beta$-catenin response transcription (CRT) induced with Wnt3a by promoting $\beta$-catenin phosphorylation at Ser33/Ser37/Thr41 and its subsequent degradation in human retinal pigment epithelial (RPE) cells. Wnt5a decreased the levels of vascular endothelial growth factor (VEGF), tumor necrosis factor- $\alpha$ (TNF- $\alpha$ ), and nuclear factor-kB (NF-kB), which was up-regulated by Wnt3a. Furthermore, Wnt5a increased E-cadherin expression and decreased cell migration by down-regulating Snail expression, thereby abrogating the Wnt3a-induced epithelial-mesenchymal transition (EMT) in human RPE cells. Our findings suggest that Wnt5a suppresses the pathogenic effects of canonical Wnt signaling in human RPE cells by promoting $\beta$-catenin phosphorylation and degradation. Therefore, Wnt5a has significant therapeutic potential for the treatment of AMD. [BMB Reports 2015; 48(9): 525-530]
\end{abstract}

\section{INTRODUCTION}

Age-related macular degeneration (AMD) causes irreversible vision loss in elderly people as a consequence of the progressive degeneration of the retinal pigment epithelium (RPE), retina, and choriocapillaries (1). Early-stage AMD is characterized by the formation of extracellular deposits, called drusen, between Bruch's membrane and the RPE and/or abnormalities in the RPE (2). The later stages of AMD are classified

${ }^{*}$ Corresponding author. Tel: +82-2-910-5732; Fax: +82-2-910-5739; E-mail: ohsa@kookmin.ac.kr

${ }^{\#}$ These authors contributed equally to this work.

http://dx.doi.org/10.5483/BMBRep.2015.48.9.140

Received 3 July 2015, Revised 20 July 2015, Accepted 27 July 2015

Keywords: Age-related macular degeneration, $\beta$-catenin, Canonical Wnt pathway, Retinal pigment epithelial cells, Wnt5a into two categories: exudative AMD (wet form) and geographic atrophy (dry form). In exudative AMD, angiogenic factors, such as vascular endothelial growth factor (VEGF), are secreted from retinal and RPE cells, promoting the formation of new vessels from the choroid and thereby inducing subretinal fluid accumulation, hemorrhage, and scarring (3). Geographic atrophy (GA) involves gradual degeneration of RPE and photoreceptor cells within the macular area, resulting in vision loss (4). While AMD pathogenesis remains to be elucidated, retinal oxidative stress and inflammation have been shown to play pathogenic roles in $\operatorname{AMD}(5,6)$.

The $\mathrm{Wnt} / \beta$-catenin pathway controls diverse developmental processes and homeostasis $(7,8)$. A key regulator of this pathway is the amount of intracellular $\beta$-catenin, a transcription coactivator. In the absence of Wnt ligand, $\beta$-catenin is phosphorylated by the destruction complex, consisting of casein kinase 1 (CK1), glycogen synthase kinase-3 3 (GSK-3 3 ), adenomatous polyposis coli (APC), and the scaffold protein axin, at residues Ser45, Thr41, Ser37, and Ser33 (9). These phosphorylation sites are then recognized by F-box $\beta$-transducin repeat-containing protein $(\beta-\operatorname{TrCP})$, a component of the ubiquitin ligase complex, which results in $\beta$-catenin degradation $(10,11)$. Upon association of Wnt ligands (Wnt1, Wnt3a, and Wnt8) with the receptor Frizzled (Fz) and low-density lipoprotein receptor-related protein 5/6 (LRP5/6) co-receptors, the destruction complex is negatively regulated, leading to the accumulation of intracellular $\beta$-catenin (12). Then, $\beta$-catenin translocates into the nucleus, where it forms a complex with the T-cell factor/lymphocyte enhancer factor (TCF/LEF) transcription factor family, thereby activating the expression of its target genes, including c-myc, cyclin D1 (CCND1), and matrix metalloproteinase-7 (MMP-7) (13-15).

Aberrant upregulation of the $\mathrm{Wnt} / \beta$-catenin pathway has been observed in the retina and RPE of AMD animal models (16). Levels of LRP5/6 and intracellular $\beta$-catenin are elevated in laser-induced choroidal neovascularization (CNV) models $(17,18)$. Intravitreal injection of a monoclonal anti-LRP6 antibody (Mab2F1) efficiently suppresses the $\mathrm{Wnt} / \beta$-catenin pathway, thereby ameliorating neovascularization (17). In addition, ectopic expression of a constitutively active mutant $\beta$-catenin $(\mathrm{S} 37 \mathrm{~A})$ induce the expression of angiogenic and proinflammatory

ISSN: 1976-670X (electronic edition)

Copyright (C) 2015 by the The Korean Society for Biochemistry and Molecular Biology

c) This is an open-access article distributed under the terms of the Creative Commons Attribution Non-Commercial License (http://creativecommons.org/licenses/by-nc/4.0) which permits unrestricted non-commercial use, distribution, and reproduction in any medium, provided the original work is properly cited. 
factors such as vascular endothelial growth factor (VEGF), tu-

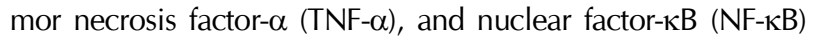
in human RPE cells and normal rat retinas (16). Furthermore, Wnt signaling promotes epithelial-mesenchymal transition, which impairs RPE barrier function and leads to the degenerative disease of the RPE such as AMD $(16,19)$. Therefore, attenuating the $W n t / \beta$-catenin pathway could be used as a potential strategy for treating AMD. In this study, we found that Wnt5a inhibited the $\mathrm{Wnt} / \beta$-catenin pathway by promoting $\beta$-catenin phosphorylation/degradation, thereby preventing the pathogenic role of the $\mathrm{Wnt} / \beta$-catenin pathway in RPE cells.

\section{RESULTS}

Wnt5a inhibits the Wnt/ $\beta$-catenin pathway in human RPE cells The effect of Wnt5a on the canonical Wnt pathway varies in different cells, tissues, and organisms $(23,24)$. Thus, we investigated whether Wnt5a could affect the $\mathrm{Wnt} / \beta$-catenin pathway in human RPE cells. To do this, ARPE-19 and hTERT-RPE- 1 cells were transiently transfected with the TOPFlash, a synthetic $\beta$ catenin/Tcf-dependent firefly luciferase (FL) reporter, followed by incubation with Wnt3a-conditioned medium (Wnt3a-CM). Wnt3a-CM up-regulated TOPFlash activity in both ARPE-19 and hTERT-RPE-1 cells (Fig. 1A). The addition of Wnt5a-conditioned medium (Wnt5a-CM) decreased the Wnt3a-CM-stimulated $\beta$-catenin response transcription (CRT) (Fig. 1A). In contrast, Wnt3a-CM and Wnt5a-CM did not affect the activity of FOPFlash, a negative control reporter with mutated $\beta$-catenin/ Tcf binding elements (Fig. 1A). Next, we determined the amount of intracellular $\beta$-catenin regulating CRT in the $\mathrm{Wnt} / \beta$-catenin pathway by western blot analysis with an anti- $\beta$-catenin antibody. Treatment of ARPE-19 and hTERT-RPE- 1 cells with Wnt5a-CM reduced the cytoplasmic level of $\beta$-catenin accumulated as a response to Wnt3a-CM (Fig. 1B). These results suggest that Wnt5a attenuates the $\mathrm{Wnt} / \beta$-catenin pathway by down-regulating the level of intracellular $\beta$-catenin in human RPE cells.

\section{Wnt5a promotes $\beta$-catenin phosphorylation and degradation in human RPE cells}

To examine whether the reduction of cytoplasmic $\beta$-catenin protein by Wnt5a was due to the repression of $\beta$-catenin gene expression in human RPE cells, we performed semi-quantitative RT-PCR to determine the expression level of $\beta$-catenin mRNA. In contrast to $\beta$-catenin protein expression, mRNA expression of $\beta$-catenin was unchanged by treatment of $\mathrm{Wnt} 3 \mathrm{a}-\mathrm{CM}$ and/or Wnt5a-CM (Fig. 2A). Next, we used MG-132 proteasome inhibitor to explore whether Wnt5a-induced $\beta$-catenin down-regulation was mediated by the proteasomal degradation pathway. As shown in Fig. 2B, down-regulation of $\beta$-catenin in response to Wnt5a-CM was substantially abrogated when ARPE-19 cells were incubated with MG-132, suggesting that Wnt5a inhibits $\mathrm{Wnt} / \beta$-catenin signaling via proteasome-dependent $\beta$-catenin degradation rather than by repressing $\beta$-catenin gene expression in human RPE cells. Phosphorylation at the N-terminal Ser33/
Ser37 residues plays an essential role in proteasome-dependent degradation (25). Therefore, we determined whether Wnt5a could induce $\beta$-catenin Ser33/37/Thr41 phosphorylation by western blot analysis with a phospho-specific $\beta$-catenin antibody. In consistent with previous reports (11), incubation of ARPE-19 cells with Wnt3a-CM suppressed $\beta$-catenin Ser33/Ser37 phosphorylation (Fig. 2C). Moreover, Wnt5a-CM restored $\beta$-catenin Ser33/ Ser37 phosphorylation in the presence of Wnt3a-CM (Fig. 2C).

\section{Wnt5a down-regulates the levels of angiogenic/inflammatory} factors in human RPE cells

Activation of the $\mathrm{Wnt} / \beta$-catenin pathway is known to significantly up-regulate the expression of angiogenic and inflammatory factors in human RPE cells (16). Given the fact that
(A)

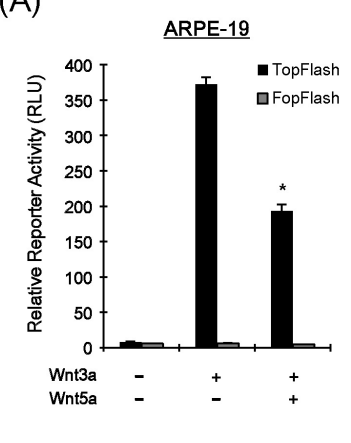

(B)
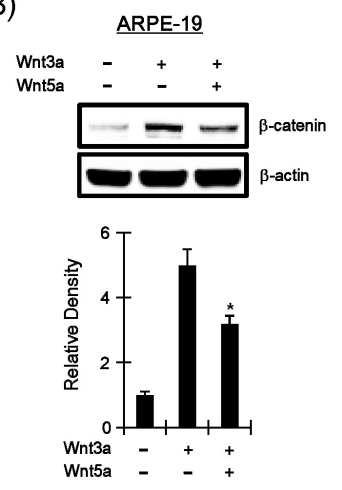
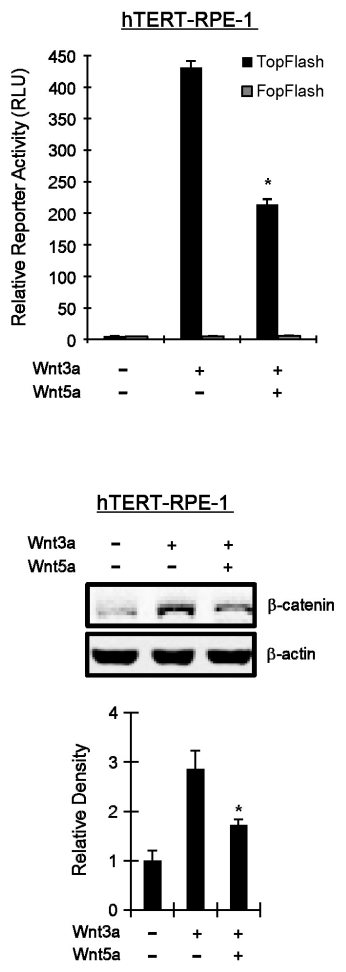

Fig. 1. Wnt5a downregulates the levels of $\beta$-catenin in human retinal pigment cells. (A) ARPE-19 and hTERT-RPE-1 cells were cotransfected with TOPFlash and pCMV-RL plasmids and incubated with Wnt3a-CM and/or Wnt5a-CM for $24 \mathrm{~h}$. Luciferase activities were measured at $48 \mathrm{~h}$ post transfection. TOPFlash activity was reported as relative light units (RLU) normalized to Renilla luciferase activity. Results were the average of three experiments, and the bars indicate standard deviations. ${ }^{* P}<0.05$, compared to the Wnt3a$\mathrm{CM}$ treated group. (B) Cytosolic proteins were prepared from ARPE19 and hTERT-RPE-1 cells treated with Wnt3a-CM and/ or Wnt5a-CM for $24 \mathrm{~h}$ and were subjected to western blotting with an anti- $\beta$-catenin antibody. Blots were re-probed with an anti-actin antibody as loading control. ${ }^{*} \mathrm{P}<0.05$ compared to the Wnt3a-CM treated group. 
(A)

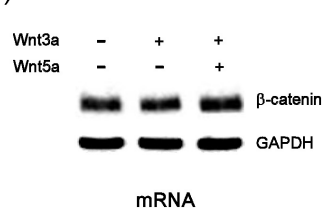

(B)

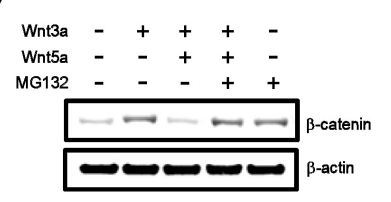

(C)

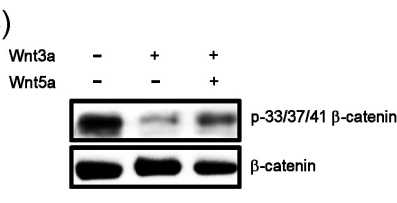

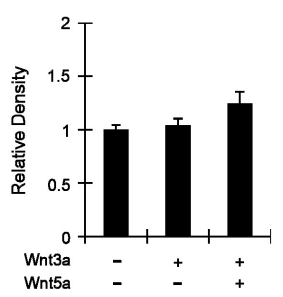
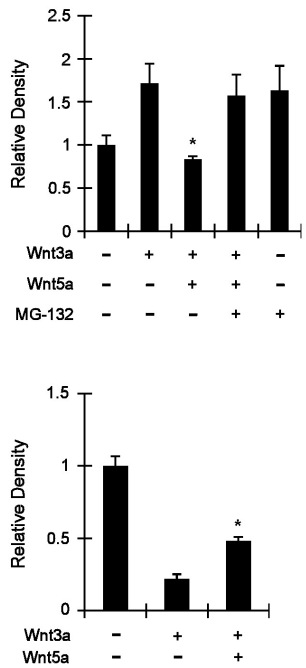

Fig. 2. Wnt5a inhibits the canonical Wnt pathway by promoting $\beta$-catenin phosphorylation and degradation in human retinal pigment epithelial cells. (A) Semi-quantitative RT-PCR of $\beta$-catenin and GAPDH using cDNA of total RNA extracted from ARPE-19 cells treated with Wnt3a-CM and/or Wnt5a-CM for $24 \mathrm{~h}$. (B) Cytosolic proteins were prepared from ARPE-19 cells that were incubated with Wnt3a-CM and/or Wnt5a-CM and exposed to MG-132 (20 $\mu \mathrm{M})$ for $8 \mathrm{~h}$. Proteins were subjected to western blotting with an anti- $\beta$-catenin antibody. Protein blot was re-probed with an anti-actin antibody as loading control. (C) Cytosolic proteins were prepared from ARPE-19 cells that were incubated with Wnt3a-CM and/or Wnt5a-CM and then subjected to western blotting with anti-phospho-Ser33/37/Thr41- $\beta$ catenin or $\beta$-catenin antibody. The same amount of $\beta$-catenin was loaded into each lane. In (A-C), the histogram shows the average volume density corrected for the loading control $(n=3)$ and bars indicate standard deviations group. ${ }^{*} \mathrm{P}<0.05$ compared to the Wnt3a-CM treated group.

Wnt5a suppresses the $\mathrm{Wnt} / \beta$-catenin pathway, we examined whether Wnt5a could represses the expression of angiogenic and inflammatory factors. In consistent with previous results (16), western blot analysis showed that the levels of VEGF, $\mathrm{NF}-\mathrm{KB}$, and TNF- $\alpha$, which are known pathogenic factors in age-related macular degeneration and diabetic retinopathy, were increased in ARPE-19 and hTERT-RPE-1 cells treated with Wnt3a-CM (Fig. 3A, B). However, Wnt5a-CM suppressed the Wnt3a-induced up-regulation of these factors in ARPE-19 and hTERT-RPE-1 cells (Fig. 3A, B).

(A)
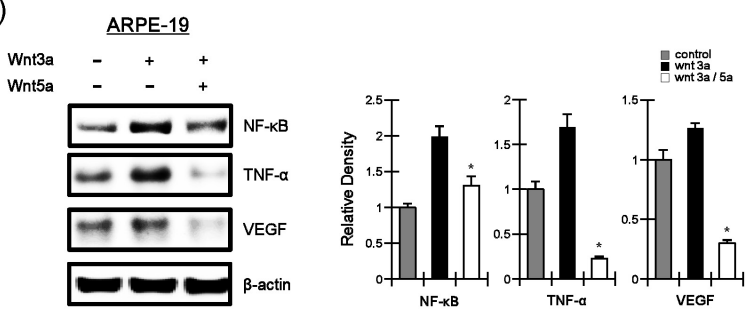

(B)
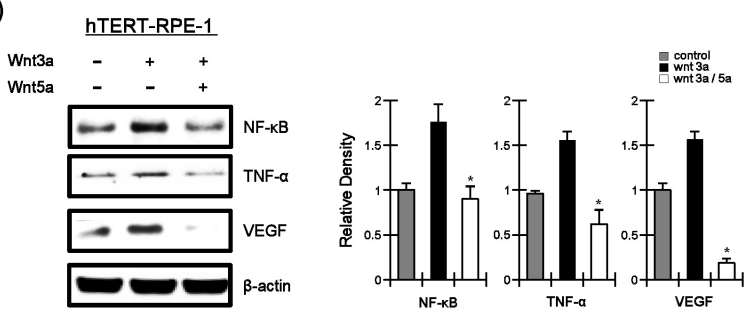

Fig. 3. Wnt5a downregulates the levels of angiogenic/inflammatory factors in human RPE cells. Total proteins were prepared from ARPE-19 (A) and hTERT-PRE-1 (B) cells treated with Wnt3a-CM and/or Wnt5a-CM and subjected to western blot analysis with antibody against NF- $\kappa B$, TNF- $\alpha$, or VEGF. The blots were re-probed with anti-actin antibody as loading control. The histogram shows the average volume density corrected for the loading control $(\mathrm{n}=$ 3) and bars indicate standard deviations group. ${ }^{*} \mathrm{P}<0.05 \mathrm{com}-$ pared to the Wnt3a-CM treated group.

\section{Wnt5a suppresses epithelial-mesenchymal transition in human RPE cells}

Epithelial-mesenchymal transition (EMT) is characterized by the loss of epithelial cell-cell contacts with a decrease in the epithelial adhesion molecule E-cadherin (26). EMT impairs RPE structural integrity, leading to retinal degenerative diseases such as AMD (27). As shown in Fig. 4A and B, incubation of ARPE-19 cells with Wnt3a-CM resulted in significant down-regulation of E-cadherin at both protein and mRNA levels. However, the addition of Wnt5a-CM nullified the effect of Wnt3a-CM on E-cadherin expression (Fig. 4A, B). Next, we analyzed ARPE-19 cell migration in response to Wnt3a-CM and/or Wnt5a-CM. Wnt3aCM consistently increased ARPE-19 cell migration. However, co-incubation of Wnt3a-CM and Wnt5a-CM inhibited cell migration (Fig. 4C), indicating that Wnt5a suppresses $\mathrm{Wnt} / \beta$-catenin-induced EMT in RPE cells.

\section{Wnt5a down-regulates Snail protein by promoting Snail phosphorylation}

Snail is a zinc finger transcription factor that mediates EMT by binding to E-box motifs located in the E-cadherin promoter region to repress E-cadherin expression (28). To investigate the mechanism underlying Wnt5a-mediated E-cadherin repression, we analyzed Snail protein expression by western blot analysis 
with an anti-Snail antibody. As shown in Fig. 4D, incubation of ARPE-19 cells with Wnt3a-CM induced accumulation of Snail protein. However, Wnt5a-CM nullified Wnt3a-mediated Snail stabilization (Fig. 4D). Since CK1/GSK-3ß-mediated Snail
(A)

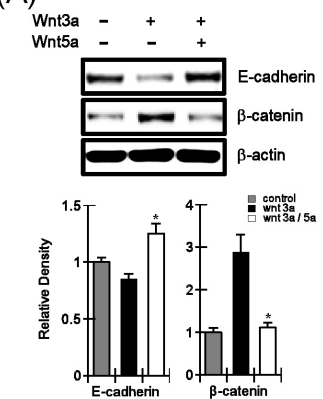

(C)

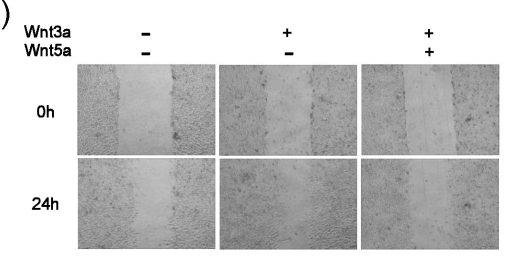

(D)

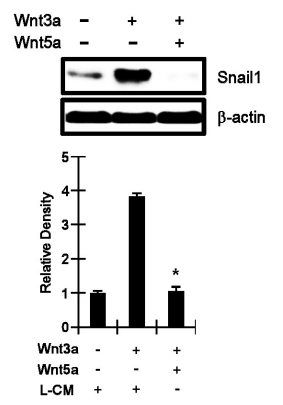

(B)

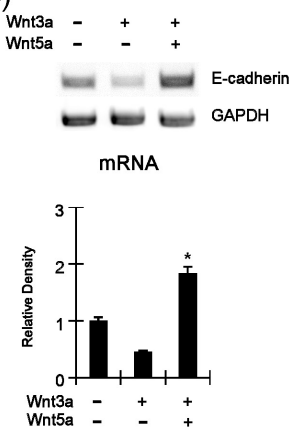

(E)

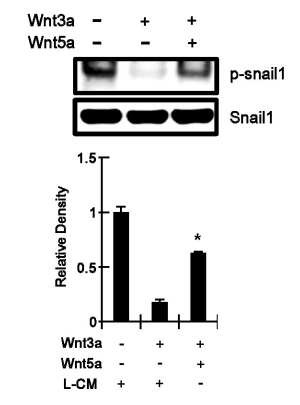

Fig. 4. Wnt5a suppresses epithelial-mesenchymal transition in human RPE cells. (A) Cytosolic proteins were prepared from ARPE-19 cells and subjected to western blotting with antibody against E-cadherin or $\beta$-catenin. The blot was re-probed with anti-actin antibody as loading control. (B) Semi-quantitative RT-PCR for E-cadherin and GAPDH was performed using CDNA of total RNA extracted from ARPE-19 cells. (C) ARPE-19 cells were grown to confluence, scratched using a razor blade, and treated with Wnt3a-CM and/or Wnt5a-CM. Representative images of cell migration at $0 \mathrm{~h}$ and $24 \mathrm{~h}$ post treatment. (D) Total proteins were prepared from ARPE-19 cells and subjected to western blotting with antibody against Snail. The blot was re-probed with anti- $\beta$-actin antibody as loading control. (E) Total proteins were prepared from ARPE-19 cells and subjected to western blotting with anti-phospho-Snail or Snail antibody. The same amount of Snail was loaded into each lane. In (A, B, D and E), the histogram shows the average volume density corrected for the loading control $(n=3)$ and bars indicate standard deviations group. ${ }^{*} \mathrm{P}<0.05$ compared to the Wnt3a-CM treated group. phosphorylation is a prerequisite for $\beta$-TrCP-dependent Snail degradation (29), we determined the status of Snail Ser96 phosphorylation after Wnt3a-CM and/or Wnt5a-CM treatment in ARPE-19 cells. When GSK-3 $\beta$ activity was inhibited by Wnt3aCM, Snail Ser96 phosphorylation was decreased (Fig. 4E). The addition of Wnt5a-CM rescued Snail phosphorylation at this residue in the presence of Wnt3a-CM (Fig. 4E). These results indicate that Wnt5a promotes Snail degradation via Ser96 phosphorylation in human RPE cells.

\section{DISCUSSION}

The $\mathrm{Wnt} / \beta$-catenin pathway is known to regulate various biological and pathological processes including AMD. Recently, Mab2F1 that specifically interacts with the extracellular domain of LRP6 has been shown to inhibit the $\mathrm{Wnt} / \beta$-catenin pathway, thereby attenuating retinal vascular leakage and retinal inflammation in a laser-induced CNV model (17). In the present study, we demonstrated for the first time that Wnt5a, which antagonizes the $W n t / \beta$-catenin pathway, down-regulated the expression of proinflammatory and angiogenic factors and suppressed epithelial-mesenchymal transition (EMT) in human RPE cells.

Several studies have reported that Wnt5a antagonizes the Wnt/ $\beta$-catenin pathway $(23,24)$, but its precise mechanism remains debatable. Wnt5a stimulates intracellular $\mathrm{Ca}^{2+}$ release to activate nuclear factor of activated T cells (NFAT), calmodulin-dependent kinase II (CaMKII), and protein kinase C (PKC) (30-32). In Xenopus embryos, XWnt5a induces translocation of XNF-AT and then mediates ventral signals by suppressing the $\mathrm{Wnt} / \beta$-catenin pathway. The $\mathrm{Wnt} 5 \mathrm{a}$-mediated $\mathrm{Ca}^{2+}$ signaling activates the TAK1-NLK pathway via CaMKII and then active NLK phosphorylates T cell factor (TCF), thereby preventing the TCF/ $\beta$-catenin complex from binding to DNA. Recently, PKC $\alpha$ has been shown to negatively regulate the $\mathrm{Wnt} / \beta$-catenin pathway through $\beta$-catenin phosphorylation and degradation. However, Topol et al. (33) have reported that Wnt5a induces $\beta$-catenin degradation through induction of Siah2, which interacts with adenomatous polyposis coli (APC) and promotes $\beta$-catenin ubiquitination. In this study, we found that $\mathrm{Wnt} 5 \mathrm{a}$ destabilized $\beta$-catenin protein in part by increasing $\beta$-catenin phosphorylation at Ser33/Ser37 residues. Further studies are needed to determine the mechanism underlying Wnt5a-mediated $\beta$-catenin degradation in RPE cells.

The $\mathrm{Wnt} / \beta$-catenin pathway has been reported to up-regulate vascular endothelial growth factor (VEGF) gene expression (34). In addition, the $\mathrm{Wnt} / \beta$-catenin pathway stimulates the generation of reactive oxygen species (ROS), which can accumulate in the form of oxidized macromolecules in RPE cells, leading to retinal degeneration (35). ROS subsequently acti-

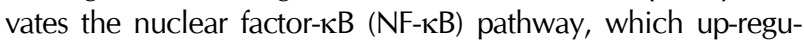
lates the expression of proinflammatory factors, such as tumor necrosis factor-a (TNF- $\alpha$ ), in RPE cells (36). The current study demonstrated that $\mathrm{Wnt} 5 \mathrm{a}$ repressed the expression levels of VEGF, NF- $\kappa B$ and TNF- $\alpha$, which were up-regulated by activa- 
tion of the $\mathrm{Wnt} / \beta$-catenin pathway.

Cell adhesion molecule E-cadherin plays important roles in maintaining the epithelial phenotype. Its expression is mainly regulated by transcription factor Snail. Snail binds to E-box consensus sequences in the E-cadherin promoter and repress the expression of E-cadherin at transcriptional level (28). Snail is normally maintained at low levels in cells through CK1/GSK$3 \beta$-mediated phosphorylation and subsequent $\beta$-TrCP-dependent proteasomal degradation (29). Activation of the $\mathrm{Wnt} / \beta$-catenin pathway negatively regulated GSK-3 $\beta$, leading to inhibition of Snail phosphorylation and up-regulation of Snail protein levels (37). In addition, the inflammatory cytokine TNF- $\alpha$ has been shown to stabilize Snail protein through the activation of the NF-кB pathway (38). Our results revealed that Wnt5a reduced the levels of Snail through promoting Snail phosphorylation/ degradation and suppressing the TNF $\alpha / N F-\kappa B$ pathway, thereby increasing the expression of E-cadherin in human RPE cells.

In conclusion, our findings demonstrated that Wnt5a suppressed the pathogenic effects of the $\mathrm{Wnt} / \beta$-catenin pathway in human RPE cells. Wnt5a promoted $\beta$-catenin phosphorylation and degradation, thereby reducing the levels of proinflammatory and angiogenic factors, such as NF- $\mathrm{kB}$, TNF- $\alpha$, and VEGF. In parallel, Wnt5a induced Snail phosphorylation and degradation, thereby increasing the expression of E-cadherin and inhibiting cell migration. Taken together, our results might provide valuable insights to assist in the development of effective therapeutics for AMD.

\section{MATERIALS AND METHODS}

\section{Cell culture}

ARPE-19 cells, hTERT-RPE- 1 cells, Wnt5a-secreting L cells, and Wnt3a-secreting $L$ cells were obtained from American Type Culture Collection (Manassas, VA) and maintained in Dulbecco's modified Eagle's medium (DMEM) supplemented with $10 \%$ fetal bovine serum (FBS), $120 \mu \mathrm{g} / \mathrm{ml}$ penicillin, and $200 \mu \mathrm{g} / \mathrm{ml}$ streptomycin. HEK293-FL reporter (TOPFlash) and control (FOPFlash) cells were established as described previously (20). Wnt5a- and Wnt3a-conditioned media (Wnt5a-CM and Wnt3a$\mathrm{CM})$ were prepared by culturing Wnt3a-secreting $\mathrm{L}$ cells in DMEM with $10 \%$ FBS for four days. The media were harvested and sterilized using a $0.22-\mu \mathrm{m}$ filter. Fresh media was added and cells were cultured for another three days. Culture media was again collected and combined with the previous media.

\section{Plasmids, transfection, and luciferase assay}

Reporter plasmid pTOPflash was obtained from Upstate Biotechnology (Lake Placid, NY). Plasmid pCMV-RL was purchased from Promega (Madison, WI). Transfections were performed using Lipofectamine 2000 (Invitrogen) according to manufacturer's instructions. Luciferase assay was performed using Dual Luciferase Assay Kit (Promega).

\section{Western blot analysis}

Cytosolic fractions were prepared as described previously (21). Proteins were separated by SDS-PAGE using $4-12 \%$ gradient gel (Invitrogen) and transferred to nitrocellulose membranes (Bio-Rad, Hercules, CA). These membranes were blocked with $5 \%$ nonfat milk and probed with anti- $\beta$-catenin (BD Transduction Laboratories), anti-phospho- $\beta$-catenin (Cell Signaling), anti-VEGF (Santa Cruz), anti-p65 (Santa Cruz), anti-TNF- $\alpha$ (Santa Cruz), anti-Snail 1 (Santa Cruz), or anti-actin (Cell Signaling) antibody. Membranes were then incubated with horseradish-peroxidaseconjugated anti-mouse IgG (Santa Cruz) or anti-rabbit IgG (Santa Cruz) antibody and visualized using ECL system (Santa Cruz). To determine the levels of phosphorylation, relative amounts of $\beta$-catenin and Snail1 protein were quantitated using densitometry (Multi Gauge V2.2). Based on the density of each $\beta$ catenin and Snail1 protein band, the same amount of $\beta$-catenin and snail was adjusted and loaded into each lane.

\section{RNA extraction and semi-quantitative RT-PCR}

Total RNA was isolated using TRIzol reagent (Invitrogen) in accordance with the manufacturer's instructions. cDNA synthesis, reverse transcription, and polymerase chain reaction (PCR) were performed as described previously (22). PCR products were separated onto $2 \%$ agarose gels and stained with ethidium bromide.

\section{Cell migration assay}

ARPE-19 cells grown to confluence on $30-\mathrm{mm}$ cell culture dishes were treated with Wn3a-CM and/or Wnt5a-CM. A scratch was made into the cell layer using a razor blade. After incubating for $24 \mathrm{~h}$, cells were washed with phosphate-buffered saline (PBS) and the scratched areas were photographed.

\section{Statistical analysis}

Student's $t$-tests were used to compare means between control and experimental groups. All experiments were performed three times. Statistical significance was considered when $P$ value was less than 0.05 . Results were presented as the mean \pm SD.

\section{ACKNOWLEDGEMENTS}

This work was supported by the Fundamental Technology Program (2012M3A9B2028335) through the National Research Foundation of Korea (NRF) funded by the Ministry of Science, ICT \& Future Planning.

\section{REFERENCES}

1. Bhutto I and Lutty G (2012) Understanding age-related macular degeneration (AMD): Relationships between the photoreceptor/retinal pigment epithelium/Bruch's membrane/ choriocapillaris complex. Mol Aspects Med 33, 295-317

2. Bonilha VL (2008) Age and disease-related structural changes in the retinal pigment epithelium. Clin Ophthalmol 


\section{$2,413-424$}

3. Smith AG and Kaiser PK (2014) Emerging treatments for wet age-related macular degeneration. Expert Opin Emerg Drugs 19, 157-164

4. Sunness JS (1999) The natural history of geographic atrophy, the advanced atrophic form of age-related macular degeneration. Mol Vis 5, 25

5. Beatty S, Koh H, Phil M, Henson D and Boulton M (2000) The role of oxidative stress in the pathogenesis of age-related macular degeneration. Surv Ophthalmol 45, 115-134

6. Augustin AJ and Kirchhof J (2009) Inflammation and the pathogenesis of age-related macular degeneration. Expert Opin Ther Targets 13, 641-651

7. Peifer $M$ and Polakis $P$ (2000) Wnt signaling in oncogenesis and embryogenesis-a look outside the nucleus. Science 287, 1606-1609

8. Wodarz A and Nusse R (1998) Mechanisms of Wnt signaling in development. Annu Rev Cell Dev Biol 14, 59-88

9. Liu C, Li Y, Semenov M, Han C et al (2002) Control of beta-catenin phosphorylation/degradation by a dual-kinase mechanism. Cell 108, 837-847

10. Latres E, Chiaur DS and Pagano M (1999) The human F box protein $\beta$-TrCP associates with the Cul1/Skp1 complex and regulates the stability of $\beta$-catenin. Oncogene 18, 849-854

11. Aberle H, Bauer A, Stappert J, Kispert A and Kemler R (1997) $\beta$-Catenin is a target for the ubiquitin-proteasome pathway. EMBO J 16, 3797-3804

12. Miller JR (2002) The Wnts. Genome Biol 3, REVIEWS3001

13. He TC, Sparks AB, Rago C et al (1998) Identification of CMYC as a target of the APC pathway. Science 281, 1509-1512

14. Tetsu $O$ and McCormick F (1999) $\beta$-Catenin regulates expression of cyclin D1 in colon carcinoma cells. Nature 398, 422-426

15. Crawford HC, Fingleton BM, Rudolph-Owen LA et al (1999) The metalloproteinase matrilysin is a target of beta-catenin transactivation in intestinal tumors. Oncogene 18, 2883-2891

16. Zhou T, Hu Y, Chen Y et al (2010) The pathogenic role of the canonical Wnt pathway in age-related macular degeneration. Invest Ophthalmol Vis Sci 51, 4371-4379

17. Hu Y, Chen Y, Lin M, Lee K, Mott RA and Ma JX (2013) Pathogenic role of the Wnt signaling pathway activation in laser-induced choroidal neovascularization. Invest Ophthalmol Vis Sci 54, 141-154

18. Chen Y, Hu Y, Lu K, Flannery JG and Ma JX (2007) Very low density lipoprotein receptor, a negative regulator of the wnt signaling pathway and choroidal neovascularization. J Biol Chem 282, 34420-34428

19. Chen HC, Zhu YT, Chen SY and Tseng SC (2012) Wnt signaling induces epithelial-mesenchymal transition with proliferation in ARPE-19 cells upon loss of contact inhibition. Lab Invest 92, 676-687

20. Gwak J, Park S, Cho M et al (2006) Polysiphonia japonica extract suppresses the $\mathrm{Wnt} / \beta$-catenin pathway in colon cancer cells by activation of NF- $\kappa$ B. Int I Mol Med 17, 1005-1010

21. Dignam JD, Lebovitz RM and Roeder RG (1983) Accurate transcription initiation by RNA polymerase II in a soluble extract from isolated mammalian nuclei. Nucleic Acids
Res 11, 1475-1489

22. Park S, Gwak J, Cho M et al (2006) Hexachlorophene inhibits Wnt//-catenin pathway by promoting Siah-mediated $\beta$-catenin degradation. Mol Pharmacol 70, 960-966

23. Topol L, Jiang X, Choi H, Garrett-Beal L, Carolan PJ and Yang Y (2003) Wnt-5a inhibits the canonical Wnt pathway by promoting GSK-3-independent $\beta$-catenin degradation. J Cell Biol 162, 899-908

24. Mikels AJ and Nusse R (2006) Purified Wnt5a protein activates or inhibits $\beta$-catenin-TCF signaling depending on receptor context. PLoS Biol 4, e115

25. Valenta T, Hausmann G and Basler K (2012) The many faces and functions of $\beta$-catenin. EMBO J 31, 2714-2736

26. Gumbiner, BM (2000) Regulation of cadherin adhesive activity. J Cell Biol 148, 399-404

27. Hirasawa M, Noda K, Noda S et al (2011) Transcriptional factors associated with epithelial-mesenchymal transition in choroidal neovascularization. Mol Vis 17, 1222-1230

28. Li H, Li M, Xu D, Zhao C, Liu G and Wang F (2014) Overexpression of Snail in retinal pigment epithelial triggered epithelial-mesenchymal transition. Biochem Biophys Res Commun 446, 347-351

29. Yook JI, Li XY, Ota I, Fearon ER and Weiss SJ (2005) Wnt-dependent regulation of the E-cadherin repressor snail. J Biol Chem 280, 11740-11748

30. Dejmek J, Säfholm A, Kamp Nielsen C, Andersson T and Leandersson $\mathrm{K}$ (2006) Wnt-5a/Ca ${ }^{2+}$-induced NFAT activity is counteracted by Wnt-5a/Yes-Cdc42-casein kinase 1alpha signaling inhuman mammary epithelial cells. Mol Cell Biol 26, 6024-6036

31. Pereira C, Schaer DJ, Bachli EB, Kurrer MO and Schoedon G (2008) Wnt5A/CaMKII signaling contributes to the inflammatory response of macrophages and is a target for the antiinflammatory action of activated protein $\mathrm{C}$ and interleukin-10. Arterioscler Thromb Vasc Biol 28, 504-510

32. Kohn AD and Moon RT (2005) Wnt and calcium signaling: $\beta$-catenin-independent pathways. Cell Calcium 38, 439-446

33. Topol L, Jiang $X$, Choi $H$, Garrett-Beal L, Carolan PJ and Yang Y (2003) Wnt-5a inhibits the canonical Wnt pathway by promoting GSK-3-independent $\beta$-catenin degradation. J Cell Biol 162, 899-908

34. Easwaran V, Lee SH, Inge L et al (2003) $\beta$-Catenin regulates vascular endothelial growth factor expression in $\mathrm{CO}^{-}$ lon cancer. Cancer Res 63, 3145-3153

35. Winkler BS, Boulton ME, Gottsch JD and Sternberg $P$ (1999) Oxidative damage and age-related macular degeneration. Mol Vis 5, 32

36. Zhou T, Hu Y, Chen Y et al (2010) The pathogenic role of the canonical Wnt pathway in age-related macular degeneration. Invest Ophthalmol Vis Sci 51, 4371-4379

37. Zhou BP, Deng J, Xia W, li YM, Gunduz M and Hung MC (2004) Dual regulation of Snail by GSK-3 $\beta$-mediated phosphorylation in control of epithelial-mesenchymal transition. Nat Cell Biol 6, 931-940

38. Wu Y, Deng J, Rychahou PG, Qiu S, Evers BM and Zhou BP (2009) Stabilization of Snail by NF-KB is required for inflammation-induced cell migration and invasion. Cancer Cell 15, 416-428 